This is an electronic reprint of the original article. This reprint may differ from the original in pagination and typographic detail.

Author(s): Rönkä, Anna; Sevón, Eija; Malinen, Kaisa; Salonen, Eija

Title: $\quad$ An examination of nonresponse in a study on daily family life : I do not have time to participate, but I can tell you something about our life

Year: $\quad 2014$

Version:

Please cite the original version:

Rönkä, A., Sevón, E., Malinen, K., \& Salonen, E. (2014). An examination of nonresponse in a study on daily family life : I do not have time to participate, but I can tell you something about our life. International Journal of Social Research Methodology, 17(3), 197-214. https://doi.org/10.1080/13645579.2012.729401

All material supplied via JYX is protected by copyright and other intellectual property rights, and duplication or sale of all or part of any of the repository collections is not permitted, except that material may be duplicated by you for your research use or educational purposes in electronic or print form. You must obtain permission for any other use. Electronic or print copies may not be offered, whether for sale or otherwise to anyone who is not an authorised user. 


\section{An examination of nonresponse in a study on daily family life: I don't have time to participate, but I can tell you something about our life.}

The aim of this study was to look at the issue of nonresponse and self-selection bias in the context of a family study on daily family life. Data on the participating families and refusers were gathered as part of the wider Palette study in which questionnaires and diaries were used as data collection methods. On the basis of these data $(\mathrm{N}=208$ participating families and 119 refuser families), we profile the families left outside the study. The parents who declined to participate in the Palette study were asked to fill in a short refusal form which included questions concerning their family background and reasons for refusal, and they were also asked to write freely about their everyday life. We found the refuser families to have less educated mothers and more children than the participating families. On the basis of a qualitative analysis three life situations which refusers considered too demanding to allow participation in the study were found. The challenges of reaching non-participants and the generalizability of the findings are discussed.

Keywords: family research, diary study, families with young children, nonresponse, self-selection bias 


\section{Introduction}

One of the challenges of quantitative family research is that the samples are very often self-selected. Researchers have succeeded in persuading well educated and motivated families to participate but have failed to motivate participation in families where the parents work in jobs requiring less education (Groves, 2006; Karney et al., 1995; Krokoff, 1990). A sample is considered to be biased if the individuals who participate in a study (respondents) differ in a systematic and relevant way from those who do not participate (nonrespondents). The term self-selection bias (also known as nonresponse bias) is applied to this phenomenon (Braver \& Bay, 1992).

The aim of this study was to look at the issue of nonresponse in the context of a family study focusing on daily family life. We discuss this problem with special reference to diary studies where the purpose is to gather data on daily life. Can the picture of everyday life received from diary studies be considered accurate and valid when some of the targeted families are left outside the study? On the basis of our data on participants and refusers, we attempt to profile the families who purposefully remained outside of the study.

\section{Non-response and self-selection bias in family studies}

Researchers (e.g., Braver \& Bay, 1992; Dillman, Eltinge, Groves \& Little, 2002; Steele \& Durrant, 2009) recognize different types of subject loss. Subject loss may be due to the inability to locate or contact all members of the targeted sample (non-locaters) or the inability to gain compliance from potential respondents who have been contacted (refusers). In addition, incapacity of the respondent may be a reason for nonparticipation. 
Such incapacity may be related, for example, to language problems or deficiency in cognitive capacities. The present study focused on purposeful refusing. Groves and Couper (1998) grouped the factors that typically influence survey participation. These factors, which either encourage or discourage participation, include social environmental influences (such as survey-taking climate), attributes of the sample persons (e.g., personal interests, civic activity) and survey protocols (e.g. recruitment process, mode of data collection, burden imposed on the participant by the method).

As part of this study, we discuss the role of the study protocol in nonresponse. One of the most important protocol-related factors that affect study participation is the degree to which the data collection burdens the participants (Groves \& Couper, 1998; Steele \& Durrant, 2009). The more demanding the data collection is from the point of view of the participants, the greater is likely to be the problem of nonresponse. In family studies, the use of diaries as a data collection method has expanded enormously (e.g., Rönkä, Malinen, Kinnunen, Tolvanen \& Lämsä, 2010). In diary studies, in which the data collection usually lasts for a week or two, and family members are asked to provide frequent reports about their family life, the problem of nonresponse is of particular concern (e.g., Bianchi, Robinson \& Milkie, 2006; Bolger, Davis \& Rafaeli, 2003; Schneider \& Waite, 2005).

In recruiting the participants, a crucial issue is the data gathering protocol. When this requires multiple family members as participants, the recruitment process, including obtaining consent and maintaining the sample, is especially challenging (Lewis, 2009; Neumark, Stommel, Given \& Given, 2001). In such a situation, the interactional 
dynamics of the activities and conversations shared between the participants and study personnel become paramount (Lewis, 2009; Maynard \& Shaeffer, 1997).

As many researchers (Costigan \& Cox, 2001; Roggman, Boyce, Cook \& Cook, 2002) have noted, it is difficult to evaluate self-selection bias because researchers do not usually have information about non-participants. Earlier studies on self-selection bias have found that, in any group of participants in a study, those who are well-adjusted, of higher socio-economic status and with higher education tend to be overrepresented (Bianchi, Robinson \& Milkie, 2006; Karney et al., 1995; Krokoff, 1990, Steele \& Durrant, 2009), although some different findings have also been reported (Lynn, Burton, Kaminska, Knies \& Nandi, 2012). Higher education and high socio-economic status, in turn, are correlated with several aspects of family life, such as parenting styles. In their literature review, Hoff, Laursen and Tardif (2002) present several research findings showing that parents with high education and high socioeconomic status are more authoritative and less authoritarian and permissive than other parents.

The problem of self-selectiveness has to do with gender as well. Persuading fathers to participate in family studies has proved to be more challenging than persuading mothers (see Costigan \& Cox, 2001; Fabiano, 2007; Lewis, 2009: Roggman et al., 2002). It is also possible that researchers have been less interested in involving fathers in studies, as noted by Phares, Lopes, Fields, Kamboukos and Duhig (2005). Such gender bias has consequences of two kinds. On the one hand, many findings about family life are in fact results about the lives of mothers. This is also related to the fact that family research has focused largely on mother-child dyads, with fathers systematically excluded from the research design. On the other hand, when fathers do participate, they do not necessarily 
represent the full range of fathers. Costigan and Cox (2001) found that in families where the fathers participated, higher educational attainment and higher occupational status were overrepresented (cf. Roggman et al., 2002).

Nonresponse per se is not always a problem in a study; the main point is whether nonresponse causes sample bias. Kalton (as cited in Braver \& Bay, 1992) states that the results obtained from the sample should be only negligibly biased if the proportion of non-respondents is very small, or if the nonparticipants and the respondents are similar in relation to the variables under scrutiny. Furthermore, as Groves (2006) points out, whether nonresponse is a problem depends on the relationship between the reason for nonresponse and the phenomenon studied. Where the reasons for nonresponding are independent of the target phenomenon, the data in this respect will be unbiased. The reasons for nonresponding, however, may include factors that affect the phenomenon under scrutiny. For example, in the case of family studies, parental education has been found to be linked both with nonresponding and with several other aspects of family life. Furthermore, the target phenomenon itself may also be a cause of response propensity, thereby increasing possible bias. This could be the case, for example, if busy families are the object of study: if the busiest families choose to remain outside the study because of their hectic life situation, then the picture gathered by the study will be systemically biased (cf. Bianchi et al., 2006, 30-33, 184).

\section{The present study}

The purpose of this methodological study was to examine nonresponse in a sample of families where some of these refused to participate in a study on daily family life. We focused on the following three research questions. First, what differences, if any, are 
there between the parents who purposefully refused to participate in the family study and those who agreed? What relevance, if any, does the form of the data collection (questionnaire only, questionnaire and diary) have for nonresponse? Since previous studies have shown that participating in a diary study is especially demanding, we expected that the participants in our diary study would be more educated than those who participated in the survey study alone. Second, what are the reasons for nonparticipation? We assumed that the reasons behind refusals would include, for example, lack of interest and fear that the study would demand too much time and effort. Third, how do the parents who refused to participate describe their daily family life? By qualitatively analysing the written descriptions of the refusers, we hoped to understand the life situations in which participation was considered difficult or unattractive.

\section{Method}

\section{Participants and refusers}

The data on the refusers was gathered as a part of the broader Palette study on everyday family life in families with young children. The data were collected at the end of 2006 and the participating families were recruited via day-care centres located in a university town and its environs in the region of Central Finland. The families had to have at least one child under the age of seven. Both spouses' participation was encouraged but not required. Information brochures about the study were distributed to the parents via children's lockers in the target day care centres $(\mathrm{N}=25)$. At the time of the study, the number of children in these day care centres was 1028 . The number of potential participating families was, however, lower as some families had more than one child in 
day care. We estimate that the information brochure reached about 900 families. The parents were asked to return a short form distributed along with the brochure regardless of whether or not they participated. For those willing to participate, this form included contact-related questions and, for those who refused full participation, a few questions on the family's background and the reasons for refusal. Refusers were also asked to describe their everyday family life in their own words. For those who were willing to participate in the study, research materials were sent to their homes and requested to be returned by post. The questionnaires concerned everyday family life, work-family interaction, parenting styles, parenting stress, the marital relationship and child well-being, temperament and day-care. Not all the families who were willing to participate returned the questionnaires, although they were reminded once. Intensive diary data covering a one-week time span were collected at the end of the year 2006.

Altogether, data were obtained for 157 parental pairs, 47 mothers ( 25 single parents and 22 with a partner who declined to participate and 4 fathers ( 2 single parents and 2 with a partner who declined to participate. Hence, a total of 208 families were represented in the study. The response rate was approximately $23 \%$, which although low is rather typical in current surveys (Porter, 2004). 118 families (13\%) were unwilling to participate and returned a refusal form. The refusal form was filled in by 109 women and 9 men. The majority of families (64\%) did not react at all. As the information brochures were distributed by the day-care personnel, exact information on the number of parents who did not react to the invitation to take part in the study is not available. 


\section{Variables and questions}

Background variables. In both the questionnaire filled in by the participants and the refusal form, we asked about the following background factors: education, age, family type and the number of children in the family (see Table 1 for scale details). In the refuser families only one parent, either the mother or father, filled in the form.

Reasons for refusal. The parents who refused to participate in the Palette study were also asked about their reasons for refusal. To make responding as quick and simple as possible, five reasons, one or more of which could be selected, were offered (see Table 2 for options). These options were based on the research literature on refusals in family studies (e.g., Braver \& Bay, 1992; Schneider \& Waite, 2005) Furthermore, the refusers were asked to give their reasons for refusal in their own words.

Refusers' descriptions of their everyday family life. The refusers were offered the possibility to write about their everyday life. The instruction was "If you like, you can describe the everyday life of your family-its good and bad moments-in the space below."

\section{Analyses}

As part of the quantitative analysis, the background variables on the participants (questionnaire and diary; questionnaire only, no diary) and refusers were compared by using ANOVAs and t-tests for continuous variables, and cross tabulations, chi-square tests, Cramer's V measure of association for nonparametric statistics and standardized residuals for discrete variables. 
To shed further light on the refusers' unwillingness to participate, their writings about their daily family life were studied. More specifically, two overlapping types of texts, answers written under the option "Some other reason" on the refusal form in response to the question "Why did you refuse?" and the refusers' descriptions of their daily life, were analysed qualitatively in tandem. Altogether 17 parents (16 mothers, one father) gave written answers to the above open question on the reason for refusal and 37 parents (35 mothers, 2 fathers) wrote descriptions about their daily family lives. Nine parents supplied both possibilities, and hence at least one short narrative was provided by 46 families.

Thematic categorization. First, the descriptions (54 in total) were read through separately by two persons and content-analyzed. The unit of analysis was an utterance (altogether 104 utterances) that formed a clearly separate thematic unit in the description. A single description and even a single sentence in a description could contain several utterances. That is, different thematic categories could co-exist in the same description. For example, in the descriptions, children were commonly emphasized both as the meaning of life and as a challenge in the everyday life of the family. The descriptions varied from short, one-sentence statements to long and rich descriptions of daily life.

Analysis of patterns of daily family life. Second, the narratives of daily life written by 37 parents were selected for closer analysis. Each description of daily family life in its entirety was grouped according to the most prevalent feature of daily life into one of four separate patterns representing different family life situations. The reason for typifying the descriptions was to gain a deeper understanding of the reasons underlying families' refusal to participate in research. 


\section{Results}

\section{Comparison between refusers and participants in the background variables}

Table 1 presents the background information given by the refusers and the participants. Statistically significant differences were found in two variables. First, among mothers, higher education was less frequent among the refusers than participants. More specifically, when compared to the participants, the refusers less often had a higher university-level degree and more often upper secondary education only. Among the fathers no connection between level of education and willingness to respond was found. To evaluate the strength of the association between mother's and father's education and the willingness to respond, we used Cramer's V Measure of Association for Nonparametric Statistics. The resulting Cramer's V values were $.295(p=.000)$ for mother's education and $.127(\mathrm{p}=.504)$ for father's education. On the basis of these analyses, mother's education contributed participation more than father's education.

Second, the refusers had more children than the participating families. There were more families with four or more children and fewer families with only one child among the refusers than participants.

\section{-Insert table 1 about here-}

To make more elaborate comparisons between the refusers and the different types of participants, we divided the participants into those who filled in both the questionnaires and diaries (107 families; 107 mothers and 88 fathers) and those who filled in the questionnaires only (101 families; 97 mothers and 73 fathers). The comparison between these three groups (refusers, diary participants, no-diary participants) showed significant differences in the same variables as in the previous 
analyses: mother's education $\left(\chi^{2}(10,321)=31.62, p<.001\right)$ and the number of children in the family $(F(2,322)=3.04, p<.05)$. Among the refusers, mothers with a higher academic degree or postgraduate degree were under-represented. In addition, mothers with upper secondary education only were over-represented among the refusers and under-represented among the no-diary participants. The refusers also had more children than either of the participant groups.

Insert table 2 about here-

\section{Reasons for refusal}

According to the parents' answers, the most usual reason for refusal was lack of time: over half of the refusers chose this option (see Table 3). Another common reason for refusal was that the research seemed to require too much effort. For some refusers, the bad timing of the diary research was also an obstacle to participation. On the other hand, lack of interest in the research topic and the unwillingness of the respondent's partner to participate were less commonly cited as reasons for refusal. Nearly 14 percent of the refusers mentioned some other reason, such as the need to protect the privacy of the family, a change in their life situation (their children will not be in day care during the research week), participation in some other study or a belief that the study was worthless. These other reasons were subjected to a more detailed qualitative, thematic content analysis together with the refusers' descriptions of their everyday family life. 


\section{Themes and patterns of daily family life}

The qualitative analysis of written descriptions produced eight thematic categories related to the everyday lives of families and the possible reasons behind refusal. The thematic categories and an utterance exemplifying each category are shown in Table 4. Three thematic categories were the most dominant: children as the meaning of life, hectic daily family life, and work-related restrictions and work demands.

-----------Insert table 4 about here-----------

The analysis of family patterns based on the short narratives given by 37 parents was started by identifying the most prevalent feature of daily life in each description. The results yielded four different patterns of daily family life. Daily family life was described as 1) filled with alternating ups and downs (18 families), 2) demanding and difficult to cope with (6 families), 3) new and exceptional (6 families) and 4) regular and wellfunctioning (7 families). In Figure 1, these four patterns are presented along two continua of daily life: first, an easiness - demandingness continuum, and second, a predictableness - unpredictableness or change in life situation continuum. Demandingness refers to the presence or absence of descriptions of strain and difficulties, and predictableness to the possibility or impossibility of having a sense of coherence, continuance and progress in the family's daily life. On the first continuum, the first two patterns of daily family life were situated close to the demandingness end and on the second continuum close to the unpredictable end. The third pattern, in turn, was situated in the middle of the first continuum and at the unpredictability and change end of the second continuum. The fourth pattern was situated at the easiness and predictability ends of the two continua.

Below, the different patterns of daily family life are described in detail. 
----------Insert figure 1 about here-----------

Daily family life filled with alternating ups and downs. This first pattern of daily family life, daily life as alternating ups and downs, was the most common pattern and visible in 18 written descriptions. It was typified by shifting between easiness and demandingness and by fluctuation between predictableness and unpredictableness. Daily family life was described as a constant alternation of good and bad moments:

Some days go without mishaps and a lot of shouting, whereas on some days the show starts straightaway in the morning [...] Ups. Downs. (Mother, 27 years, three children)

The most common challenge mentioned by the refusers in these families was a busy and hectic life situation which stemmed from combining paid employment with housework and family life. Many parents complained of hurry, lack of time and difficulties in coping with daily life. There seemed to be too little time for all the areas of life - work, parenting, the spousal relationship and personal life - and many reported that it was the latter two that suffered most from this situation. In order to enable their daily life to function, they had constantly to rearrange timetables.

Our daily life is very busy, constant reconciliation of schedules (hobbies, work). There is too little free time to spend together with the family, when one can do what one wants and when there is no housework or other duties to do. (mother, 38 years, two children).

Working life was mentioned 11 times by the refusers in this group as a factor adding strain to and making demands on their families' daily lives. In these descriptions, strain related to working life derived not only from the writer's own work situation, but 
also from his or her partner's work situation. Mothers, mostly, mentioned their partner's long and difficult working hours as a cause of extra strain on their daily family life. Today's working life is hectic and demanding, which tends to use up too many resources (...). (Mother, 38 years, one child)

On the whole, although this group of refusers brought into the spotlight several challenges in their daily lives that they felt would have made participation in the study difficult, such negative issues were combined with more easygoing interludes.

Daily family life as demanding and difficult to cope with. The second pattern of daily family life, described by six families, was characterized by the persistent demandingness of daily life. Compared to the previously described pattern, these descriptions laid heavier emphasis on demandingness, exhaustion and not being able to cope with daily family life properly. They felt tired and inadequate under the strain caused by their manifold work load. These descriptions tended to take the form of rather laconic statements referring to the parents' tiredness, exhaustion and inadequacy.

Sometimes there seems to be too little time for the children when you do housework after a day at work and then you have to go to bed early in order to wake up in time. (Mother, 32 years, two children)

Single parenthood was described as a situation that made everyday life more challenging: A single parent has very few happy moments! (Mother, 32 years, 2 children) In these descriptions many reasons for the experience of demandingness were given, such as a new life situation, heavy work demands and the challenges of rearing several children at different ages at the same time. In this pattern of family life, it 
was high amounts of demandingness and strain caused by these different circumstances that was the most heavily foregrounded.

Daily family life as new and exceptional. The third pattern of daily family life, described by six families, was characterized by a major life change and the novelty of the current life situation. Thus, this pattern was better characterized on the continuum of predictability - change, with the emphasis on the changing nature of daily family life, than on the continuum of easiness - demandingness. However, in many of these families' descriptions, the high level of demandingness of their current life change also emerged. Their daily family life had recently seen major upheaval: the birth of a child, changes in day care arrangements or the mother's return to working life. Situations like the following were described as relevant to the family's decision to refuse to participate: A 3-year-old adopted daughter arrived in our family a year ago. Our older daughter is 12 years old and teenage is knocking at the door. Your research is interesting, important and valuable. At this moment, we parents are just trying to find enough time for our children in addition to careers and housework - and sometimes just a little for ourselves. (Mother, 39 years, two children).

The parents in this category wrote that they would need time and peace to adapt to their new life situation, and therefore participating in a study was not a priority. Some refusers described their situation in life as exceptional. They were in the middle of a house building project or were just moving to a new home. Such unusual situations put additional strain on the daily family life of these parents and might have contributed to their refusal to participate in the Palette study. 
Everyday life as regular and well-functioning. The fourth pattern of daily family life, described by seven families, was characterized by its easiness and predictability. In their descriptions they mentioned ordinary, regular routines:

The so-called normal daily life of a family with children, with the same repetitive routines. (Mother, 33 years, two children)

Furthermore, free time and shared family time during weekends were mentioned and in some cases emphasised as a positive resource:

At last we parents have a little time of our own. (Mother, 41 years, 2 children) These parents did not write about any particular difficulties or challenges in their lives that would have made participation in the study difficult. They had decided not to participate for other reasons. Possibly, their reason for refusing was connected with their desire to protect their own free time. Or they might have considered their lives to be too ordinary and flat to interest researchers.

\section{Discussion}

The aim of this study was to shed light on the issue of nonresponse in the context of a family study focusing on daily family life. This is a problematic task because it is hard to obtain information about nonresponders. Our strategy for analyzing nonresponse was to focus on the families who purposefully refused to participate by asking them for specific background information and their reasons for refusal. It should be noted that this approach only yielded information on some of the non-responding families; a large proportion of the refuser families did not react at all to our requests. One could speculate whether the refusers, i.e. the active parents who returned the refusal form, were refusers 
in the strong sense. It is possible that we succeeded in reaching a number of pseudo refusers, that is parents who normally, under different circumstances, would have participated. This should be borne in mind in generalizing the results. However, the problem of non-response is widespread (Porter, 2004), and unfortunately very often either ignored or viewed as self-evident by researchers. We feel that we succeeded in gaining additional understanding on how to avoid and minimize non-response in future research.

\section{Insights into refuser characteristics, nonresponse and self-selection bias}

In accordance with earlier studies (e.g., Groves, 2006; Karney et al., 1995), we found that the parents who actively refused were less educated than the participating families. A new finding was that mothers' education contributed most to this. Furthermore, we succeeded better in reaching or recruiting women for our study. We base this statement on three distinct perceptions. First, the data set comprised 22 families where only the mother was willing to participate (compared to only two families where only the father was willing). Second, the number of single-mother families in our sample was bigger than that of single-father families ( 25 single-mother families compared to two singlefather families.) Third, in the refuser group, the vast majority of the refusal forms were also filled in by mothers. Almost $8 \%$ of the refusers (mainly women) reported that they would have participated had their partners also been willing). It seems that highly educated women are the most motivated to take part in family research, and it is probably due to their efforts that the whole family joins in (cf. Lewis, 2009). It is also possible that some women act as gatekeepers for men's participation, leaving men outside. Moreover, it might also be that family studies are perceived as targeted more at women. 
Another new finding was the higher number of children per family in the refuser group. In contrast, families with only one child were overrepresented among the participating families. In families with many children, the parents may be heavily burdened with child-rearing duties. This makes participation in research difficult - there is no time to fill in the questionnaires or diaries. This explanation was also supported by our qualitative data.

We identified four patterns of daily family life in the refusers' descriptions. However, the number of refusers who wrote about their lives was limited, and consequently these results must be interpreted with caution. Of the patterns of daily family life, three in particular reflected life situations which parents considered too demanding to allow participation in the study. One of these - "daily family life filled with ups and downs"- was a busy family life caused by a high number of children and a lot of work both inside and outside the home. Life was busy $24 / 7$, admitting no possibility to participate. Second, for a smaller group of families - "daily family life as stressful and difficult to cope with" - the life situation behind refusal stemmed even more clearly from exhaustion and strain. The third situation in life behind refusal -"daily family life as new and exceptional" - was living through an important life change or upheaval in the family, such as a new baby, new workplace or building a house, which sapped the family's energy.

Interestingly, however, not all the parents left outside the study complained of daily life as stressful. There were also families among the refusers who described their life as regular and well-functioning. Furthermore, on the basis of our other analyses, there appeared also to be other, less common reasons behind refusal: research participation 
fatigue, which can easily happen in a university town; lack of motivation to participate on the part of spouses; and a critical attitude towards society and research in general).

It is also important to pay attention to the factors in which the participants and refusers were not found to differ. The results showed that the proportion of different family types (married or cohabiting parents, single-parent families, reconstituted families) in the two groups was similar. This is an encouraging finding, indicating that families with different structures are willing to participate in research. Furthermore, the results showed that participants and refusers did not differ in age.

We also hypothesized that the more demanding the form of participation is, the more selected the sample will be. However, we found no support for this (cf. Bianchi et al., 2006, 184). The differences between the different participant groups were nonsignificant. In other words, the diary study participants, whose engagement in the study was required for a week, were not more self-selected than those who only participated in the questionnaire study. Possibly, the diary study was considered a novel and interesting departure from more conventional methods; some parents expressed curiosity about it.

An important question remains: what effect, if any, do the kinds of differences found in this study have on the results of research on daily family life? The answer depends, according to Groves (2006), on whether the factors in question - in this study the educational level of women and the number of children in the family - are related or unrelated to the topic of interest. Where the focus of the study is on researching everyday lives in families with young children - as in the Palette study - these factors clearly affect self-selection bias. It is known, for example, that the greater the number of children, the 
more challenges there may be in combining work and family (e.g., Allen, Herst, Bruck \& Sutton, 2000). From the point of view of sample selection, this may mean that participating families with a smaller number of children have a less demanding life situation. At least, the findings of the qualitative analysis refer quite clearly to the demandingness of the refuser families' daily lives.

The connection between educational level and the quality of daily life is more complicated. First, there is evidence that lower education is linked with more traditional family roles in terms of gender inequality and the division of housework and of adultcentered, authoritarian child rearing (Hoff et al., 2002; Aunola, Nurmi, OnatsuArvilommi \& Pulkkinen, 1999). From this point of view, the sample selection in our study may indicate that the parents in the participating families' are more democratic and equal in their daily lives (also Bianchi et al., 2006, 33). Second, lower education can be seen in a more positive light when we think about work stress and a generally busy life and their possible spillover into family life. It can be speculated that more educated participants with more demanding and challenging jobs and higher time pressure at work might feel more stress and experience higher work-to-family conflict (e.g., Allen et al, 2000; Bianchi et al., 2006, 32-33). Conversely, it has been argued in relation to the $24 / 7$ society that employees in working class jobs have less control over working times and schedules, causing them to experience higher pressures in terms of accomplishing family life (Southerton, 2011).

\section{Recommendations for minimizing non-response and self-selection bias}


There are a few things researchers can do to minimize or control sample-selection bias. As Groves (2006) states, it is important to acknowledge that minimizing nonresponse does not always minimize sample-selection bias. On the contrary, reducing nonresponse may compound bias as the potential participants may differ in their sensitivity to the designs used to improve response rates. It is thus important to find appropriate and tailored ways to motivate participation, not only among those who would not usually take part in a family study but also in families that would under different circumstances participate. Steele and Durrant (2009) suggest that the training of interviewers should include information about how to target groups with lower participation rates. According to them, contact rates in field interview studies could be improved by lengthening the fieldwork period (see also Porter, 2004).

For lower educated parents, for busy or exhausted dual career families as well as for families undergoing major transitions - the subgroups of families that according to our research tend to remain outside of family research - shorter and less time consuming research protocols that avoid academic jargon are needed. Survey length is an issue that particularly affects the response rate (Porter, 2004).

To minimize nonresponse, researchers should avoid places typically visited by researchers such as university towns, where the amount of surveys has increased during recent decades (Porter, 2004) Targeting families directly - and not via an institute could work better in motivating parents to participate. Personal contact between researchers and families seems to be important in achieving this. Our strategy of distributing information leaflets to families via children's lockers in day care centres did not prove very effective in reaching families. As recommended by Fabiano (2007), researchers might need to 
schedule research protocols to better fit the timetables of working parents. Offering parents childcare to better enable them to fill out forms and give interviews could also be helpful.

To promote greater willingness to participate among fathers, we offer several recommendations, as suggested by Phares et al (2005) in the context of pediatric research: contacting fathers directly to invite them to join in the research (instead of using mothers as gatekeepers; see also Lewis, 2009); using alternative recruitment strategies (e.g., contacting fathers through their workplaces); and expanding the working definition of fathers so as to invite, for example, non-custodial fathers or non-biological father figures. In our study, the ex-partners of 22 single mothers were automatically left outside of our study; it is possible that some of them would have participated if asked. Furthermore, Fabiano (2007) suggests that questionnaire items need to be developed, piloted and validated specifically for use with fathers. In their feedback, some male participants criticized the questionnaire for lacking a male perspective. Although these actions might not increase the total number of participating families and thus decrease non-response, it would increase the amount of male participants

The finding that participation is to some extent gendered is in line with the notion that it is more challenging to persuade the couple or the whole family to participate than to motivate a single family member (see Lewis, 2009; Neumark et al, 2001). Lewis (2009) suggests contacting all the potential participants of the study directly rather than relying solely on one family member's (usually the mother's) consent. When recruiting participants, researchers should also emphasize that, as long as the family itself is willing to participate, no life situation is too ordinary or too exceptional to impede participation, 
especially in view of the fact that some of the families who refused attributed their life situation to one of these two extremes of the continuum.

Finally, it is crucial to pay attention to factors that could motivate or reinforce participation. Is there something other than payments of money or gifts? Some families might like to see researchers more actively engaged in putting research findings into policy-making practice. A further strategy might be to involve families more in the planning phase of the study, with volunteers acting as experts or consultants in formulating study protocols. In a university town, as in our study, this is something that might more easily be arranged. Should we, as researchers, change our attitude from one of studying families to studying with families?

\section{References}

Allen, T. D., Herst, D. E. L., Bruck, C. S., \& Sutton, M. (2000). Consequences associated with work-to-family conflict: A review and agenda for future research. Journal of Occupational Health Psychology, 5, 279-308.

Aunola, K., Nurmi, J-E, Onatsu-Arvilommi, T. \& Pulkkinen, L. (1999). The role of parents' self-esteem, mastery-orientation and social background in their parenting styles. Scandinavian Journal of Psychology, 40, 307-317

Bianchi, S. M., Robinson, J. P., \& Milkie, M. A. (2006). Changing rhythms of American family life. New York: Russell Sage Foundation.

Bolger, N., Davis, A., \& Rafaeli, E. (2003). Diary methods: Capturing life as it is lived. Annual Review of Psychology, 54, 579-616. 
Braver, S. L., \& Bay, C. (1992). Assessing and compensating for self-selection bias (nonrepresentativeness) of the family research sample. Journal of Marriage and the Family, 54, 925-939.

Costigan, C., \& Cox, M. (2001). Fathers' participation in family research: Is there a selfselction bias? Journal of Family Psychology, 15, 706-720.

Dillman, D. A., Eltinge, J. L., Groves, R. M., \& Little, R. J. A. (2002). Survey nonresponse in design, data collection, and analysis. In R. M. Groves, D. A.

Dillman, J. L. Eltinge, \& R. J. A. Little (Eds.), Survey nonresponse (pp. 3-26). New York: Wiley.

Fabiano, G.A. (2007). Father participation in behavioral parent training for ADHD: Review and recommendations for increasing inclusion and engagement. Journal of Family Psychology, 21, 683-693.

Groves, R. M. (2006). Nonresponse rates and nonresponse bias in household surveys. Public Opinion Quarterly, 70, 646-675.

Groves, R. M., \& Couper, M. P. (1998). Nonresponse in household interview surveys. New York: Wiley.

Hoff, E., Laursen, B., \& Tardif, T. (2002). Socioeconomic status and parenting. In M. H. Bornstein (Ed.), Handbook of parenting: Vol. 2. Biology and ecology of parenting (2nd ed., pp. 231-252). Mahwah, NJ: Erlbaum.

Karney, B. R., Davila, J., Cohan, C. L., Sullivan, K. T., Johnson, M. D., \& Bradbury, T. N. (1995). An empirical investigation of sampling strategies in marital research. Journal of Marriage and the Family, 57, 909-920. 
Krokoff, L. J. (1990). The relationship of the husband's emotional involvement to participation in research on marital relationships. Journal of Family Issues, 11, $182-190$.

Lewis, R. (2009). Recruiting parents and children into a research project: a qualitative exploration of families' decision-making processes. International Journal of Social Research Methodology, 12, 405-419.

Lynn, P., Burton, J., Karminska, O., Knies, G. \& Nandi, A. (2012). An initial look at nonresponse and attrition in Understanding Society. Understanding Society Working Paper Series No 2012-02.

Maynard, D.W., \& Schaeffer, N. C. (1997). Keeping the gate. Declinations of the request to participate in a telephone survey interview. Sociological Methods \& Research, 26, 34-73.

Neumark, D.E., Stommel, C.W., Given, C. W., \& Given, B. A. (2001). Research design and subject characteristics predicting nonparticipation in a panel survey of older families with cancer. Nursing Research, 50, 363-368.

Phares, E. L., Lopes, E., Fields, S., Kamboukos, D., \& Duhig, A. M. (2005). Are fathers involved in pediatric psychology research and treatment? Journal of Pediatric Psychology, 30, 631-643

Porter, S. R. (2004). Raising response rates: What works? New Directions for Institutional Research, 121, 5-21.

Roggman, L. A., Boyce, L., Cook, G. A., \& Cook, J. (2002). Getting dads involved: Predictors of father involvement in Early Head Start and with their children. Infant Mental Health Journal, 23, 62-78. 
Rönkä, A., Malinen, K., Kinnunen, U., Tolvanen, A.\& Lämsä, T. (2010). Capturing daily family dynamics via text messages: development of the mobile diary. Community, Work \& Family, 13 (1), 5-21.

Schneider, B., \& Waite, L. (Eds.) (2005). Being together, working apart. Dual career families and the work-life balance. Cambridge, UK: Cambridge University Press.

Southerton, D. (2011). Are we running out of time? In V. May (Ed.), Sociology of Personal Life (pp. 121-133). Hampshire, UK: Palgrave McMillian.

Steele, F. \& Durrant, G. (2009). Alternate approaches to multilevel modeling of survey noncontact and refusal. Working Paper M09/15. University of Southampton, Southampton Statistical Sciences Research Institute. 
Table 1

Background Information on Refusers and Participants

\begin{tabular}{lll}
\hline Background variable & Refusers & Participati \\
(n=118 families of & ng families \\
& which refusers'form & $(n=208 ;$ \\
& filled in by 109 women, & 204 \\
& 9 men) & mothers, \\
& & 161 \\
& & fathers) \\
\hline
\end{tabular}

Mother's age (\%)

$M(S D)$

$35.39(5.40)$

34.50

$t$-test

Father's age (\%)

$M(S D)$

$t(320)=1.42, p=.16$

$t$-test

Mother's education (\%)

1. Comprehensive school or similar

2. Vocational qualifications

$37.51(6.23)$

36.16

3. Upper secondary education

$$
t(267)=1.83, p=.07
$$

5.08

23.15

31.36

$\underline{18.72}$

4. Lower academic degree (Bachelor) or

$\underline{36.44}$

15.76

polytechnic education

5. Higher academic degree (Master)

6. Scientific postgraduate degree (Licentiate or Doctor)

$\chi^{2}$

$\underline{14.41} \quad \underline{\underline{32.51}} \underline{\underline{7.39}}$

$$
\begin{gathered}
\chi^{2}(5, n=321)=27.93, \\
p<.001
\end{gathered}
$$

Father's education (\%)

1. Comprehensive school or similar

6.60

3.13

40.57

36.88

2. Vocational qualifications

20.75

18.75

13.21

13.13

polytechnic education

5. Higher academic degree (Master)

14.15

20.63

6. Scientific postgraduate degree (Licentiate or

4.72

7.50

Doctor)

$\chi^{2}$

$$
\begin{gathered}
\chi^{2}(5, \mathrm{n}=266)=4.32, \\
p=.50
\end{gathered}
$$

Family type (\%)

Married/cohabiting couple with child/children

86.44

77.40

from the present relationship

Reconstituted family

5.08

8.65 
Single parent with child / children $\chi^{2}$

$$
\begin{gathered}
8.47 \\
\chi^{2}(2, \mathrm{n}=326)=3.95 \\
p=.14
\end{gathered}
$$

Number of children (\%) $M(S D)$ $t$-test

$$
\begin{gathered}
2.35(1.09) \\
t(206,460)=2.33, \\
p=.02
\end{gathered}
$$

Note: Absolute values of adjusted residuals for underlined figures are $\geq 2$ 
Table 2

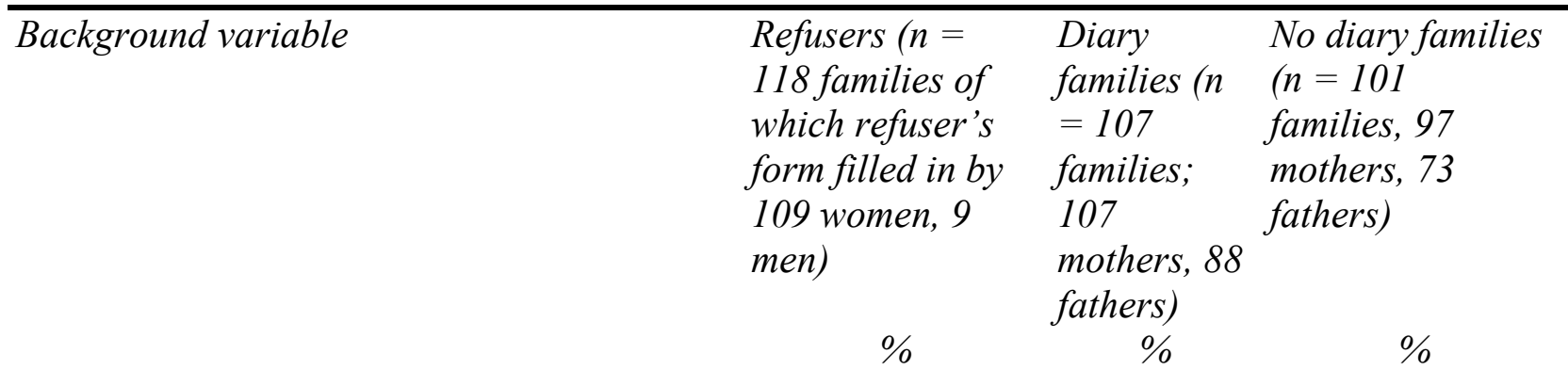

Mother's age

$M(S D)$

ANOVA

Father's age

$M(S D)$

ANOVA

Mother's education

1. Comprehensive school or similar

2. Vocational qualifications

3. Upper secondary education

4. Lower academic degree (Bachelor) or polytechnic education

5. Higher academic degree (Master)

6. Scientific postgraduate degree

(Licentiate or Doctor)

$\chi^{2}$

Father's education

1. Comprehensive school or similar

2. Vocational qualifications

3. Upper secondary education

4. Lower academic degree (Bachelor) or polytechnic education

5. Higher academic degree (Master)

6. Scientific postgraduate degree

(Licentiate or Doctor)

$\chi^{2}$

Family type

Married or cohabiting couple with

children from a present relationship

Reconstituted family (married or cohabiting couple with children from previous (and current) relationships)

Single parent with child / children
$35.39(5.40)$

34.83

$34.13(5.82)$

$F(2,321)=1.42, p=0.24$
$37.51(6.23) \quad 36.64 \quad 35.58(5.68)$
(5.67)
$F(2,268)=2.35, p=0.098$

$\begin{array}{lcc}5.08 & 1.89 & 3.09 \\ 31.36 & 18.87 & 27.84 \\ \underline{36.44} & 20.75 & \underline{16.49} \\ 11.02 & 18.87 & 12.37 \\ \underline{14.41} & 32.08 & 32.99 \\ \underline{1.69} & 7.55 & 7.22\end{array}$

$$
\chi^{2}(10, N=321)=31.619, p<.001
$$

$\begin{array}{ccc}6.60 & 3.41 & 2.78 \\ 40.57 & 36.36 & 37.5 \\ 20.75 & 17.05 & 20.83 \\ 13.21 & 14.77 & 11.11\end{array}$

14.15

19.32

22.22

4.72

9.09

5.56

$\chi^{2}(10, \mathrm{~N}=266)=6.02$

$p=0.81$

86.44

82.24

72.28

5.08

6.54

10.89

8.47

11.21

16.83 
$\chi^{2}$

Number of children

$M(S D)$

ANOVA

$$
\chi^{2}(4, \mathrm{~N}=326)=7.29, p=.12
$$

$2.35(1.09) \quad 2.08(.90)$

$F(2,322)=3.04, p=.049$ refusers $>$ all other groups 


\section{Table 3}

Reasons for Refusal to Participate in the Palette Study

\begin{tabular}{lc}
\hline Reason for refusal & Refusers (\%) \\
\hline We have no time to participate in the study & 52,5 \\
The study seems to require too much effort & 44,1 \\
The timing of the diary study is bad, and we don't want to & 13,6 \\
participate in the inquiry only & \\
I am willing to participate, my partner is not & 7,6 \\
The theme of the study does not interest me/our family & 6,8 \\
Some other reason & 13,6 \\
\hline
\end{tabular}


Table 4

Thematic Categories in Refusers' Descriptions of Their Daily Life

\begin{tabular}{|c|c|c|}
\hline $\begin{array}{l}\text { Thematic } \\
\text { categories }\end{array}$ & $\begin{array}{l}\text { Number of } \\
\text { Utterances }\end{array}$ & Example of Utterance \\
\hline $\begin{array}{l}\text { Children as the } \\
\text { meaning of life }\end{array}$ & 29 & $\begin{array}{l}\text { Children are anyway the joy of life and the greatest } \\
\text { source of meaning for us. (Mother, } 27 \text { years, three } \\
\text { children) }\end{array}$ \\
\hline $\begin{array}{l}\text { Hectic daily } \\
\text { family life }\end{array}$ & 26 & $\begin{array}{l}\text { Bustle and chaos, peace and conviviality. } \\
\text { Alternating between tears and laughter Each and } \\
\text { every day tastes like life. (Mother } 37 \text { years, two } \\
\text { children) }\end{array}$ \\
\hline $\begin{array}{l}\text { Work-related } \\
\text { restrictions } \\
\text { and work } \\
\text { demands }\end{array}$ & 17 & $\begin{array}{l}\text { We are living just an ordinary everyday life, in } \\
\text { which work takes all our extra strength. (Mother, } 35 \\
\text { years, two children) }\end{array}$ \\
\hline $\begin{array}{l}\text { Ongoing life } \\
\text { change }\end{array}$ & 10 & $\begin{array}{l}\text { I have just begun a new job after post-natal leave } \\
\text { and our youngest child has started day care. At the } \\
\text { moment these things take up all my energy. } \\
\text { (Mother, } 35 \text { years, two children) }\end{array}$ \\
\hline $\begin{array}{l}\text { Demandingness } \\
\text { of daily } \\
\text { family life }\end{array}$ & 8 & $\begin{array}{l}\text { We feel inadequate } 24 \text { hours a day. Work } \\
\text { and daily routines take a lot of time and } \\
\text { energy.(Mother, } 30 \text { years, one child) }\end{array}$ \\
\hline $\begin{array}{l}\text { Challenges of } \\
\text { rearing several } \\
\text { children in } \\
\text { different age } \\
\text { groups }\end{array}$ & 7 & $\begin{array}{l}\text { The children are } 2,4,8 \text {, and } 11 \text { years old, and thus } \\
\text { we are struggling with rebelliousness and soon with } \\
\text { puberty, which adds its own flavor to each day } \\
\text { (Mother, } 38 \text { years, four children) }\end{array}$ \\
\hline $\begin{array}{l}\text { Uninterested in } \\
\text { participating in } \\
\text { research }\end{array}$ & 6 & $\begin{array}{l}\text { We have already participated in many studies. We } \\
\text { are not able to do this any longer. (Mother, } 39 \text { years, } \\
\text { two children) }\end{array}$ \\
\hline $\begin{array}{l}\text { Language } \\
\text { problems }\end{array}$ & 1 & $\begin{array}{l}\text { We are immigrants, and that's why we have } \\
\text { difficulties in participating. (Mother, } 29 \text { years, one } \\
\text { child) }\end{array}$ \\
\hline
\end{tabular}


Figure 1

Dimensions of daily family life of refusers

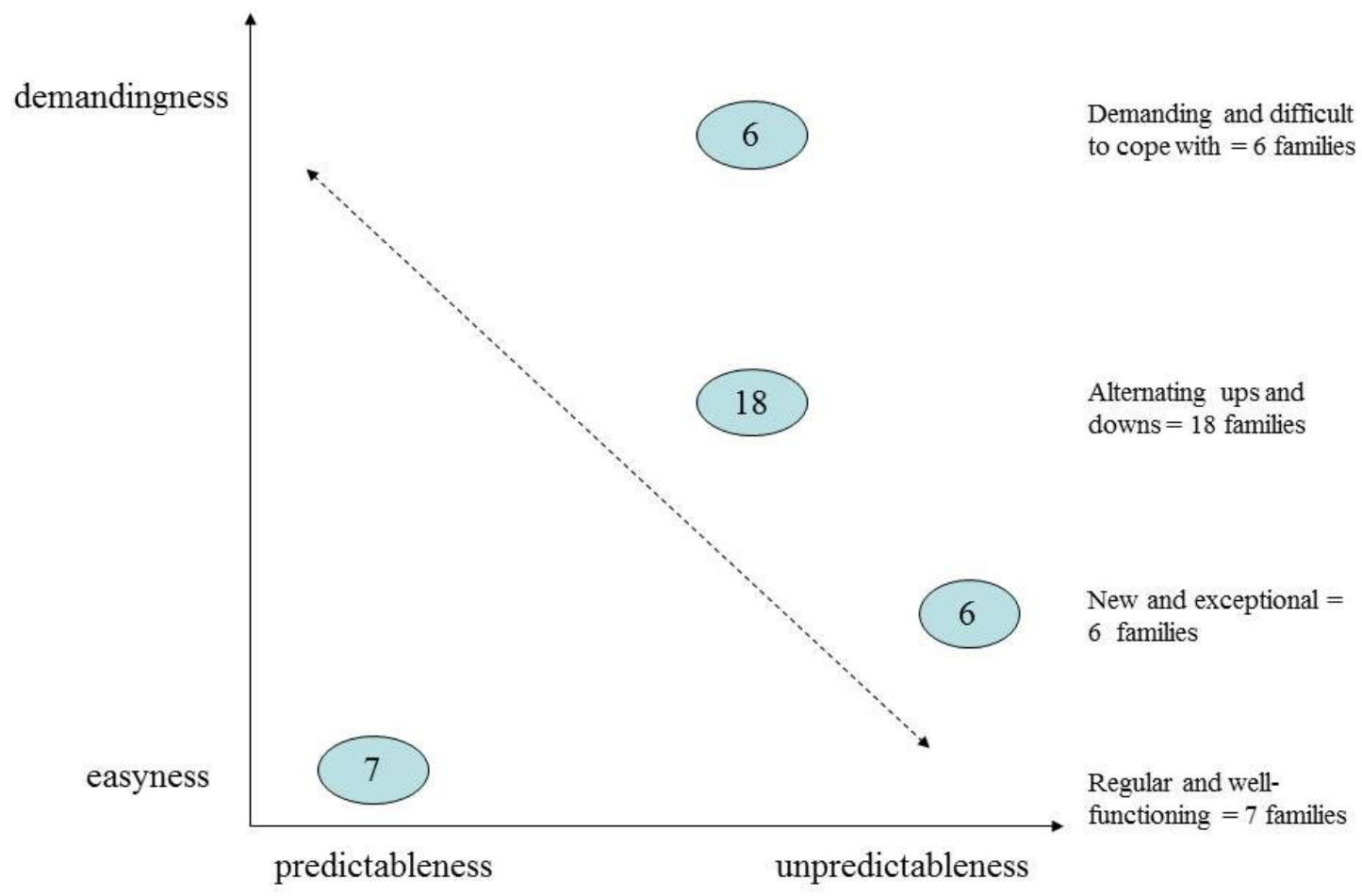

